\title{
Ancillary revelations of the Single-Ventricle Reconstruction Trial: The less excitement, the better
}

\author{
Ibrahim Abdullah, MD
}

\author{
From the Department of Pediatric Cardiothoracic Surgery, Banner Children's Specialists, Mesa, Ariz. \\ Disclosures: Author has nothing to disclose with regard to commercial support. \\ Received for publication July 24, 2017; accepted for publication July 31, 2017. \\ Address for reprints: Ibrahim Abdullah, MD, Banner Children's Specialists, 1432 S Dobson Rd, Suite 512, Mesa, \\ AZ 85202 (E-mail: iabdullah1234@gmail.com). \\ J Thorac Cardiovasc Surg 2017;154:1711 \\ $0022-5223 / \$ 36.00$ \\ Copyright (c) 2017 by The American Association for Thoracic Surgery \\ http://dx.doi.org/10.1016/j.jtcvs.2017.07.070
}

The Single-Ventricle Reconstruction Trial published by Ohye and colleagues ${ }^{1}$ in 2010 continues to occupy a seminal role in the ongoing debate about whether a modified Blalock-Taussig shunt (mBTS) or a right ventricle-to-pulmonary artery shunt offers a better outcome for patients undergoing a stage I Norwood procedure. Proponents of the mBTS shunt often argue that there is an inherent longterm advantage to avoiding a right ventriculotomy, whereas proponents of the right ventricle-to-pulmonary artery shunt cite inherent disadvantages of having coronary steal during the diastolic runoff in a mBTS. In the randomized SingleVentricle Reconstruction Trial, Ohye and colleagues ${ }^{1}$ concluded that as late as 12 months, transplant-free survival was better with the right ventricle-to-pulmonary artery shunt than with the mBTS, with no significant difference between the groups in transplant-free survival after 12 months. Perhaps more intriguing than their report, however, were the ancillary investigations done during this trial-that of adrenergic receptor $(A D R)$ genotype variations of the patients and their associations with secondary adverse events.

In the study presented in this issue of the Journal, Ramroop and colleagues ${ }^{2}$ collected buccal swab epithelial cells from the Single-Ventricle Reconstruction Trial population, extracted genomic DNA, and performed genotyping for 4 single-nucleotide polymorphisms in $3 A D R$ genes. Genotyping was also performed for 4 single-nucleotide polymorphisms and 1 insertion-deletion variant in 5 reninangiotensin-aldosterone signaling $(R A A S)$ genes. The primary outcome sought was a composite of any serious adverse event (SAE) during a 14-month follow-up after the stage I Norwood procedure, which included death, transplant, need for extracorporeal membrane oxygenation, cardiopulmonary resuscitation, shunt failure, unplanned reoperations, or necrotizing enterocolitis. They found a lower SAE-free survival during a 14-month follow-up for the $64 \%$ of patients that had the wild type ADRA2A_2790CC genotype versus the $C T / T T$ genotypes. This finding is

\section{References}

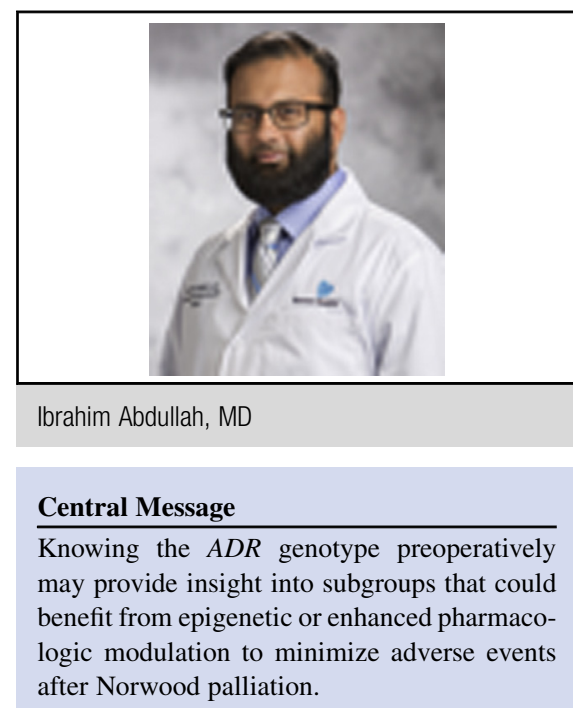

See Article page 1703.

significant in that, according to Ramroop and colleagues, ${ }^{2}$ the ADRA2A_2790CC genotype is associated with diminished feedback inhibition of norepinephrine and failure to inhibit sympathetic tone. They postulate, convincingly so, that higher sympathetic tone adversely affects systemic output and organ perfusion, resulting in the higher risk of SAEs. Although they do not have hemodynamic data to corroborate their findings, their investigation of the $A D R$ genes is very relevant to this population, because one of the primary management strategies for patients after the Norwood procedure is tailored toward achieving a balance between the systemic and pulmonary circulations. Any enhanced chronic sympathetic tone on the systemic side could offset that critical balance and place more stress on the single right ventricle. Knowing the $A D R$ genotype before the operation may provide important insight into subgroups that could benefit from epigenetic or enhanced pharmacologic modulation to minimize the risk of SAEs after the stage I Norwood palliation.

1. Ohye RG, Sleeper LA, Mahony L, Newburger JW, Pearson GD, Lu M, et al; Pediatric Heart Network Investigators. Comparison of shunt types in the Norwood procedure for single-ventricle lesions. N Engl J Med. 2010;362:1980-92.

2. Ramroop R, Manase G, Lu D, Manase D, Chen S, Kim R, et al. Adrenergic receptor genotypes influence postoperative outcomes in infants in the Single-Ventricle Reconstruction Trial. J Thorac Cardiovasc Surg. 2017;154:1703-10.e3. 